\title{
Production of GABA (gamma amino butyric acid) by Lactic Acid Bacteria
}

\author{
Moo-Chang Kook ${ }^{1}$ and Seok-Cheol Cho* \\ Department of Food and Nutrition, Seowon University, Cheongju 361-742, Korea \\ ${ }^{1}$ Department of Marin Biotechnology, Anyang University, Incheon 417-833, Korea
}

\begin{abstract}
Gamma-amino butyric acid (GABA) is a kind of pharmacological and biological component and its application is wide and useful in Korea specially, becoming aging society in the near feature. GABA is request special dose for the purposed biological effect but the production of concentrated GABA is very difficult due to low concentration of glutamic acid existed in the fermentation broth. To increase GABA concentrate using fermentation technology, high content of glutamic acid is required. For this reason, various strains which have the glutamic acid decarboxylase (GAD) and can convert glutamic acid to GABA, were isolated from various fermented foods. Most of GABA producing strains are lactic acid bacteria isolated from kimchi, especially added monosodium glutamate (MSG) as a taste enhancer. Optimizing the formulation of culture media and the culture condition, GABA conversion yield and amounts were increased. Finally GABA concentration of fermentation broth in batch or fed batch fermentation reached $660 \mathrm{mM}$ or $1000 \mathrm{mM}$, respectively. Furthermore formulation of culture media for GABA production developed commercially. Many studies about GABA-rich product have been continued, so GABA-rich kimchi, cheese, yogurt, black raspberry juice and tomato juices has been also developed. In Korea many biological effects of GABA are evaluated recently and GABA will be expected to be used in multipurpose.
\end{abstract}

Key words: lactic acid bacteria, fermentation, GABA, kimchi, high concentration

\section{Introduction}

Meat consumption per capita is increasing depending on the increase of the national income. According to the Korea Rural Economic Institute, annual meat consumption per capita in 2011 was $40.4 \mathrm{~kg}$ (average consumption per capita was $110.6 \mathrm{~g} /$ day) and it has increased to $4.2 \%$ $(1.6 \mathrm{~kg})$ compared with that of $2010,38.7 \mathrm{~kg}$. Compared with $32 \mathrm{~kg}$ consumption in 2005, consumption amount is increased about 26.2\% (KREI, Agricultural and livestock industry products statistics, 2011). The increase of meat consumption is changing to factory-style and corporatestyle in domestic livestock industry. The factory-style livestock industry means adapting livestock's ecology to the industrial scale. So, it affects the increase of scale of livestock husbandry and density. In early 2000 s, the numbers of livestock increased to three times for the chicken and five times for the pig compared with the early 1980s. Consequentially, poultry farmers raising more than 30,000

\footnotetext{
*Corresponding author: Seok-Cheol Cho, Department of Food and Nutrition, Seowon University, Cheongju 361-742, Korea. Tel: 82-43-299-8748, Fax: 82-43-299-8740, E-mail: cscho@, seowon.ac.kr
}

chickens increased to $48.9 \%$ in 2007 , whereas $0.2 \%$ in 1990 , and ones raising less than 5,000 chickens decreased to $3.4 \%$ from $97.2 \%$. This overcrowding and unnatural breeding environment gives livestock causing a lot of stress and creates a vicious cycle of weakening immune system and antibiotic overdose (Moon, 1998; Song et al., 1998).

On the other hand, the European Union banned the antimicrobial growth-promoter for formula feed since 2006 responding to the worldwide needs of safety and high-quality livestock products. Korea also banned the use of antimicrobial growth-promoter from July 2012 (Ministry for Food, Agriculture, Forestry and Fisheries. Announcement No. 2010-3; The Agriculture, Fisheries and Livestock's News. 2011). The development of various natural feed additives that can be replaced by it is completed or in progress (Kim, 2010; Lim et al., 2011).

In accordance with increasing domestic consumers' tendency to prefer eco-friendly livestock products, consumers' interest on food safety is also increasing and the development of feed additives to promote livestock's function as a way of producing eco-friendly livestock products (Lee et al., 2008; Lee, 2009). The researches and developments for functional feed additives are indispensable for both consumers and producers for the future of the livestock 
industry.

The stress arising from the overcrowding of the factory-style livestock industry as well as the sanitary problems causes infectious diseases or diarrhea by reducing livestock's immunity and finally reduces productivity and coefficient of reproduction. It is possible to rely on the facilities in order to minimize various stresses that occur when livestock breeding, but it has the cost problem. Therefore, developing a substance being able to reduce stress and using it for livestock breeding can respond effectively to the factory-style livestock industry. Besides, various environmental and nutritional stresses arising from the modern livestock industry necessarily lead to the reduced livestock growth and feed availability and result in economic losses of farmers, so the study of anti-stress functional feed additives is essential (Jung et al., 2010; Magoto et al., 2004).

$\gamma$-Aminobutyric acid (GABA) is the non-protein amino acid that is widely distributed in nature, and generated irreversibly through the $\alpha$-decarboxylation of L-glutamic acid in a reaction catalyzed by glutamate decarboxylase (GAD). GAD and GABA have been found from bacteria to higher organisms widely. GABA is well known as inhibitory neurotransmitter. The concentration of glutamate as excitable neurotransmitter and GABA is controlled by GAD (Ueno, 2000).

GABA promotes the metabolism of brain cells by increasing the oxygen supply and activating cerebral blood flow and inhibits the secretion of the vasopressin (antidiuretic hormone) by acting on the vasomotor center of medulla oblongata. Furthermore, GABA regulates growth hormone secretion, drops the blood pressure by expanding the blood vessels, and has the diuretic, anti-depressive, anti-oxidant effects, effective pain relief, as well as a medicine for the stroke treatment, especially (Hao and Schmit, 1993; Kono and Himeno, 2000; Leventhal et al., 2003; Shelp et al., 1999). In recent years, its sleep-inducing effect was proved by the animal experiment which establishes the production of serotonin and melatonin which act as sleep inducer, is facilitated significantly in the GABA-containing milk feeding group (Kim et al., 2010). The interest of GABA as a functional food ingredients has been heightened due to the recent proof of various biological functions of GABA and it is reported that GABA-reinforced soy, tea, red yeast rice and chlorella drop the blood pressure in the experiment in Spontaneously Hypertensive Rats (Abe et al., 1995; Bae, 2008; Hayakawa et al., 2004; Nakamura et al., 2000; Tsuiji et al., 1992).
GABA is available in many fruits and vegetables but the concentration is low in nature of which rang is from 0.03 to $2.00 \mu \mathrm{mol} / \mathrm{g}$-wet weights (Fougère et al., 1991; Rhodes et al., 1986), which is known to be difficult to have biological activity. However, it is reported tea contains sufficient amount of GABA to hypertensive patient, showing the effect in lowering blood pressure without any side effects. It means various functional foods can be developed in case of available concentration of GABA added.

Various researches to increase GABA contents are in progress, and the method of increasing the amount of GABA in green tea under anaerobic conditions is one of the examples (Chang et al., 1992; Sawai et al., 2001; Tsushida and Murai, 1987; Wang et al., 2006). GABA production is stimulated through the action of decarboxylase in embryos by water immersing (Saikusa et al., 1994), increasing GABA content using high-pressure and germination of brown rice (Miwako et al., 1999), producing GABA containing yogurt (Park and Oh, 2007). Most of these methods produce GABA from glutamic acid by promoting the reaction of decarboxylase existing in the natural products. Therefore, the amount of GABA is proportional to the amount of glutamic acid existing in the various materials and addition of glutamic acid should be necessary in order to obtain a high concentration of GABA.

The study for the production of high concentrations of GABA using microorganisms is progressing in order to overcome these limitations. Recently, it is reported that lactic acid bacteria isolated from variety of fermented foods such as kimchi and salted seafood produces GABA using glutamic acid as a substrate. PharmaFood company (Japan) produced GABA by conversion of monosodium glutamate using lactic acid bacteria isolated from kimchi and sells as a functional food ingredient and it has reported to produce $6.3 \mathrm{mM}$ GABA by inoculating Lactobacillus brevis IFO 12005 isolated from kimchi to Soju jigemi made from rice (Ueno et al., 1997; Yokoyama et al., 2002), $302 \mathrm{mM}$ of GABA by adding pyridoxal phosphated as a coenzyme of GAD by $L b$. paracasei NFRI 7415 isolated from Japanese traditional fermented food funasushi (Komatsuzaki et al., 2005). Recently, Yang et al. (2008) has reported to produce $78 \mathrm{mM}$ of GABA using Streptococcus salivarius in China, and domestic researchers are developing the isolation of strains producing GABA and have reported to produce $19 \mathrm{mM}, 251 \mathrm{mM}$ of GABA respectively by isolation of GABA-producing strains such as Lb. brevis OPK 3, Lb. buchneri from traditional fermented foods such as kimchi (Cho et al., 2007; Park and Oh, 2006). 
The research for the commercial production of GABA is also developing and $660 \mathrm{mM}$ of GABA produced using the 5 ton fermenter with $L b$. sakei B2-16, isolated from Kimchi (Kook et al., 2010), and fed-batch process by immobilized Lb. brevis GABA 057 strains using alginate bead has changed $12 \%$ of MSG into GABA for $48 \mathrm{~h}$ (Choi et al., 2006). It succeeded to produce $1005.8 \mathrm{mM}$ of GABA from 3.1 M MSG by Lb. brevis NCL912 isolated from Paochai in China (Li et al., 2010).

Intake of effective concentration of GABA, which is not available with the naturally enhanced GABA containing food, is available due to the increase the GABA productivity by the isolation of various strains and the study of fermentation. As a result, GABA began applying for components of the foods and cosmetics and recently functional feed additives depending on the cost of production was lowered, so it is necessary to arrange the research associated with the production of GABA by the fermentation at this point.

\section{Subject}

\section{Isolation of strains}

In Korea, most of GABA is produced by lactic acid bacteria isolated from kimchi. The traditional fermented foods such as salted seafood and sauces have been used occasionally, but it now appears that most strains, which have high conversion yield of GABA or have been studied on the production by continuous fermentation and efficacy evaluation, are lactic acid bacteria from kimchi.

GABA-producing strain isolated from aged natural cheese is used to increase GABA content in milk fermented products in Japan (Nomura et al., 1998) and various strains with GABA-producing capacity isolated from dairy foods are used as starters for milk fermentation in Korea (Park and Oh, 2006), but it has been reported that their conversion yield is lower than conversion yield of lactic acid bacteria isolated from kimchi for the production of GABA. In recent years, the high-GABA-productive yeast was isolated from the vicinity of the ocean (the Pacific Ocean) by Japanese researchers (Masuda et al., 2008). It has the advantage of increasing the GABA content of fermented bean foods by applying GABA-producing strain to yeast fermentation with beans as the main ingredient, but yet the conversion rate of glutamic acid is lower than that of lactic acid bacteria that are used in domestic for industry.

On the other hand, most of strains applied in various studies on the production of GABA are lactic acid bacte- ria isolated from kimchi, and have the advantage of verification for safety. Because there may be no problem to use for foods as raw materials by strains isolated from fermented foods which have been eaten traditionally.

In the case of health supplements or foods containing GABA by lactic acid bacteria fermentation, the additional verification procedure of safety is needed, but the safety of general foods can be recognized in case of GABAcontaining fermentation broth by the GABA producing lactic acid bacteria.

Various kinds of kimchi were used as the sample for isolation of lactic acid bacteria, and most researchers have used the commercial brand kimchi, traditional market kimchi, restaurants kimchi and homemade kimchi for the sample, because kimchi is made of a various ingredient depending on the purpose or region. And in order to isolate the superior lactic acid bacteria which convert glutamic acid to GABA, kimchi with various amount of MSG are compared, and then, one with good producer of GABA is chosen. For the first time, it is known that lactic acid bacteria used in PharmaFood company in Japan for the industrial production of GABA was isolated from kimchi and GABA-containing mung bean ferment (product name: Phyto-GABA) which is exporting to China for cosmetic raw material is known as the product using lactic acid bacteria isolated from kimchi of a domestic venture company (Park et al., 2005).

\section{Isolation of GABA producer}

First, lactic acid bacteria were isolated from kimchi, after then, strain having the producing ability of GABA was selected, and vice versa. The isolation of lactic acid bacteria from kimchi samples used the plate count medium with BCP (bromocresol purple) as a selective media, that is, adjusted to $\mathrm{pH} 6.8 \pm 0.2$ after dissolving peptone $5.0 \mathrm{~g}$, yeast extract $2.5 \mathrm{~g}$, dextrose $1.0 \mathrm{~g}$, tween $801.0 \mathrm{~g}$, L-cystein $0.1 \mathrm{~g}$, bromocresol purple $0.05 \mathrm{~g}$, agar $15.0 \mathrm{~g}$ in 1,000 $\mathrm{mL}$ of distilled water according to the Food Standards Codex (Korean Food Standards Codex. 2011).

Samples for isolation of lactic acid bacteria are spread onto the plate count medium with BCP, typically prepared kimchi from various regions is grinded with soup using a sterile homogenizer and the suitable number of single colony is obtained after dilution at a rate of about $1 / 10^{6}$ $\sim 1 / 10^{8}$. Generally, sterile saline solution or BPW (Buffered peptone water) is used for dilution in accordance with the Food Standards Codex. After cultivation for $72 \mathrm{~h}$ at 35 to $37^{\circ} \mathrm{C}$, lactic acid bacteria colonies with yellowish color are selected. 


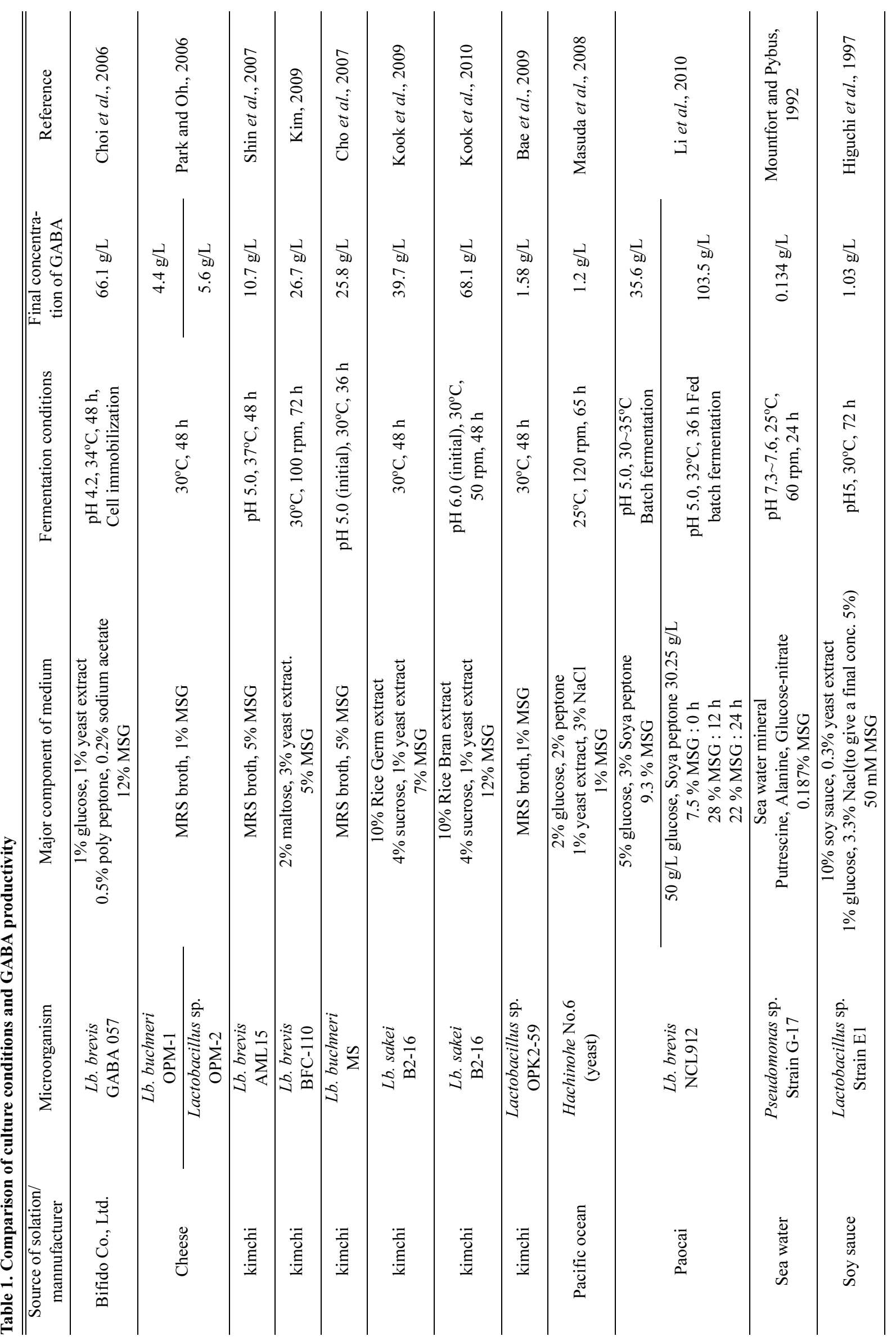


MRS medium with MSG as a source of glutamic acid is used in order to select the strains with GABA-producing capability among the isolates. GABA-producing capability of strains can be determined by analyzing the GABA content in culture broth after 3-4 d of culture with $1 \%$ level of MSG in the medium. Generally, in case of matured kimchi with MSG as a sub material, the GABA-producing strains were found and the most of them are lactic acid bacteria. There is no basis which one is more efficient, selecting lactic acid bacteria or GABA-producing bacteria but it can be a time-saving way to search preferentially strains of superior GABA-producing capability in appropriately fermented kimchi suitable for eating.

Depends on the fact that GABA-producing strain having the resistance to high concentrations of MSG primarily, isolating GABA-producing bacteria which have tolerance to high concentration of GABA. Generally, the MSG resistant strains are isolated by adding $5 \%(\mathrm{w} / \mathrm{v})$ of $\mathrm{MSG}$ in MRS medium and it is reported that the resistant strains of high concentrations of MSG are isolated by increasing to $10 \%$ of MSG content (Kim, 2009).

\section{Qualitative and quantitative analysis of GABA}

TLC (Thin Layer Chromatography) and RP-HPLC (Reverse Phage High Performance Chromatography) are used in GABA qualitative and quantitative analysis, respectively.

The qualitative analysis using TLC is assumed in order to confirm GABA-producing capability of a large number of bacteria in a short period of time. Typical developing solvent is n-Buthanol-Acetic acid- $\mathrm{H}_{2} \mathrm{O}$ [5:3:2 or 4:1:1 (v/ $\mathrm{v} / \mathrm{v}$ )], and it is modified to match the experimenters (Holdiness, 1983). Developed TLC plate is dried after applying the ninhydrin solution $(0.2 \%, \mathrm{w} / \mathrm{v}$-ethanol) as a color reagent. The spot of GABA and MSG can be easily confirmed by GABA standard solution and MSG solution because GABA and MSG are detected with the red spot when it is dried at around $60^{\circ} \mathrm{C}$ after spraying the ninhydrin solution (Fig. 1). The amount of loading sample varies by researchers and can be determined experimentally. A clear GABA spot can be obtained with $1 \mu \mathrm{L}$ of the sample removed solids fraction from the fermentation broth containing GABA by centrifugation.

Quantitative analysis of GABA uses RP-HPLC and many different protocols have been established as well as various TLC developing solvent by the researchers. First, Kook et al. (2009) modified the analysis protocols reported by Ibolya and Vasanits (1999), Tcherkas et al. (2001) for the quantitative analysis of GABA in the culture broth. After centrifugation of the sample for $10 \mathrm{~min}$ at 8,000

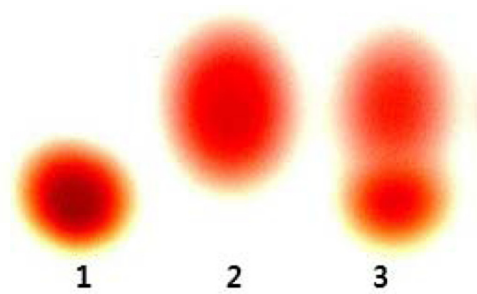

Fig. 1. TLC profile of monosodium glutamate (MSG) and gamma aminobutyric acid (GABA) during Lactobacillus brevis B3-18 fermentation. 1. MSG standard; 2. GABA standard; 3. Cultural supernatant of Lactobacillus brevis B3-18.

rpm, the supernatant were filtered with $0.45 \mu \mathrm{m}$ cellulose acetate membrane filter (Advantec, MFS. Inc., Japan) and diluted to the appropriate concentration. The analysis is carried out using RP-HPLC after derivatization process using $o$-phthaldialdehyde (OPA). The OPA solution ( $\mathrm{pH}$ 9.3 ) is made by mixing $1.0 \mathrm{~mL}$ of a methanolic OPA, 250 $\mu \mathrm{L}$ of borate buffer ( $\mathrm{pH} 9.9$ ) and $25 \mu \mathrm{L}$ of 2-mercaptoethanol. Methanolic OPA is made by dissolving $2.56 \mathrm{~g}$ of OPA in $50 \mu \mathrm{L}$ of methanol. For borate buffer, $0.2 \mathrm{M}$ potassium was put in after mixing $0.2 \mathrm{M}$ boric acid and $0.2 \mathrm{M}$ sodium hydroxide by $50: 50(\mathrm{v} / \mathrm{v}) .20 \mu \mathrm{L}$ of derivatized sample was injected into the column. RP-HPLC system is composed of Waters 2487 Dual $\lambda$ Absorbance detector, Waters 1525 Binary HPLC pump, Waters 717 plus Autosampler, U.S.A and XTerra column (Waters, RP18 $5 \mathrm{~m} \times$ $4.6 \mathrm{~mm} \times 150 \mathrm{~mm}$, U.S.A) for HPLC column. 0.05 M sodium acetate $(\mathrm{pH} 7.2)$ is mobile phase $\mathrm{A}$, and the mixture ( $\mathrm{pH} 7.2$ ) of $0.1 \mathrm{M}$ sodium acetate, acetonitrile (HPLC grade) and methanol (HPLC grade) by 46:44:10 (v/v) is mobile phase B. Mobile phase were controlled by gradient conditions. The flow rate was fixed at $1 \mathrm{~mL} / \mathrm{min}$; GABA was detected by $358 \mathrm{~nm}$ of UV detector (Fig. 2).

Kim (2009) modified the method of Chen et al. (1997) to the analysis of GABA. After centrifugation of the culture broth for $15 \mathrm{~min}$ at 3,000 rpm, the supernatant were filtered with $0.45 \mu \mathrm{m}$ CA membrane filter, the filtered sample were diluted to $0.2 \mathrm{M}$ sodium bicarbonate solution ( $\mathrm{pH} 9.8$ ) by 1:9, after then, the derivatization reagent, Dansyl chloride, mixed to the sample till $8.0 \mathrm{~g} / \mathrm{L}$. It is analyzed, after incubation for $1 \mathrm{~h}$ at $30^{\circ} \mathrm{C}$ with blocking light. The mobile phase $\mathrm{A}$ is the mixed solvent with tetrahydrofuran-methanol-50 mM pH 6.2 sodium acetate $(5: 75: 420, \mathrm{v}: \mathrm{v}: \mathrm{v})$ and the mobile phase $\mathrm{B}$ is methanol, and the gradient condition is $\mathrm{A}: \mathrm{B}=100: 0$ (0 min), 60:40 (10 $\min ), 0: 100(10 \mathrm{~min})$. The flow rate was fixed at $1 \mathrm{~mL} /$ min, the column is OptimaPak C18 $(4.6 \times 250 \mathrm{~cm})$ and its temperature is $40^{\circ} \mathrm{C}$. GABA was detected by $280 \mathrm{~nm}$ of 


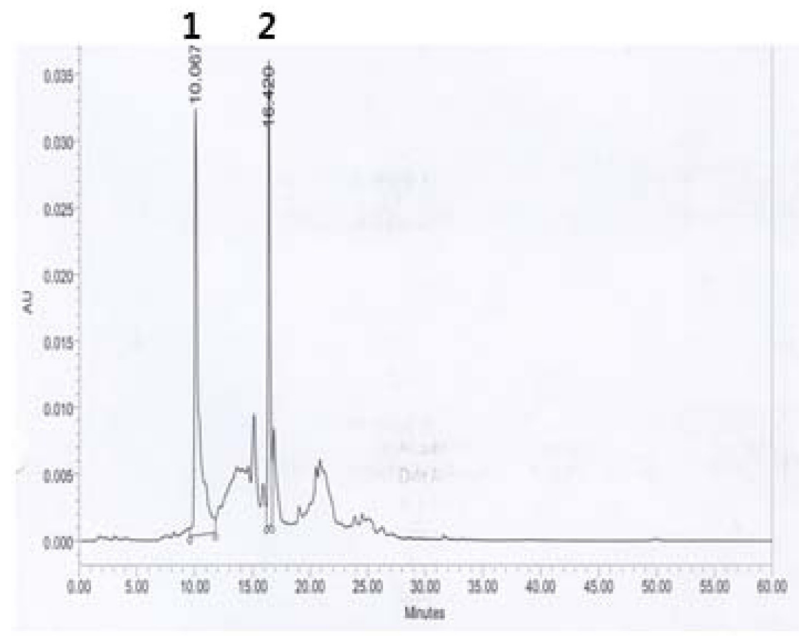

Fig. 2. RP-HPLC profile of monosodium glutamate (MSG) and gamma aminobutyric acid (GABA) during Lactobacillus brevis B3-18 fermentation. Analysis conditions: mobile phase A. 0.05 M Sodium Acetate; mobile phase B. 0.1M Sodium Acetate: Acetonitile:Methanol (46:44:10, v/v/v); Column. Xterra (C18, Waters); 1. MSG; 2. GABA

\section{UV detector.}

And, Oh and Oh (2003) modified the method of Baum et al. (1996). After adding $200 \mu \mathrm{L}$ of sample to $800 \mu \mathrm{L}$ of methanol-chloroform-water (12:5:3), GABA-containing supernatant is obtained by centrifugation for $15 \mathrm{~min}$ at $4^{\circ} \mathrm{C}$, $13,000 \mathrm{~g}$. The centrifugation is conducted again to remove impurities from the supernatant and then, it is freezedried and used after dissolving in water before the analysis. The sample dissolved in water is filtered by $0.45 \mu \mathrm{m}$ membrane and derivatized to 6-aminoquioly-N-hydroxysuccinimidyl carbonate (AQC) (Cohen and Michaud, 1993), followed analysis by amino acid analysis system (2690, Waters, USA).

There is the way to quantify the content of GABA by measuring the activity of the GABAse, not using RPHPLC but spectrophotometer (Sethi, 1993), however, it is not common in Korea. As described above, researchers apply quantitative analysis methods using RP-HPLC by some variants. Now, GABA is not listed in food ingredients or food additives and the name is not free to use, therefore there is no standardized assay. From now on, food ingredients or food additives listing and standard analysis settings will be the important task to researchers.

\section{Production of GABA by fermentation}

\section{Medium composition}

It is basic technique to culture GABA-producing bacte- ria in the optimal medium where lactic acid bacteria can proliferate actively in order to produce GABA. Generally, GABA-producing lactic acid bacteria were cultured in MRS medium at the first stage when the study on production of GABA was started, after that time, the study to examine the composition of the medium to increase the productivity of GABA was actively conducted (Choi et al., 2006; Kook et al., 2009; Kook et al., 2010; Oh, 2006; Seok et al., 2008).

Also, the optimization of medium composition for increasing the productivity of GABA and experiments to configure low-cost medium for the industrial production of GABA were carried out together (Kim, 2009; Kook et al., 2009; Kook et al., 2010). Generally, the optimal medium composition can vary depending on the strain of GABA producing lactic acid bacteria. Most of the strains isolated for the production of GABA in Korea were $L b$. brevis isolated from kimchi (Kang, 2002) and Lb. sakei, so the research on two species of lactic acid bacteria for the production of GABA has been conducted in Korea.

Therefore, the composition of the medium for the growth of GABA producing lactic acid bacteria was studied initially, and carbon source, nitrogen source and trace elements for the growth of Lb. brevis and Lb. sakei are selected through experiments in general. As a Carbon sources, dextrose, sucrose, maltose, fructose, lactose, xylose, galactose and arabinose are considered, and yeast extract, soytone, peptone, beef extract and tryptone are as nitrogen sources, which are examined as the medium for the growth of strains and the production of GABA. Magnesium sulfate, sodium acetate, manganese sulfate, ferric sulfate, calcium chloride and poly-solvate are trace elements and they are added to the medium as the mineral. The composition of medium for GABA production would not differ significantly from the medium for proliferation of lactic acid bacteria. Glucose, maltose and sucrose as carbon source were selected, and yeast extract as nitrogen source showed to be suitable and the impact of a small amount of added metal ions was weak. The composition of medium was determined at the level of less than $4 \%$ of carbon source and nitrogen source respectively and at the $0.01 \%$ level of metal ions. The medium composition can vary depending on the final product whether a high concentrations of GABA or a particular product containing GABA, and generally the medium composed of carbon source, nitrogen source and minerals adds optimal concentration of glutamic acid to match the strain's ability to produce GABA and finally is used to obtain the produced GABA (Table 2). 
Tomato paste (Cho et al., 2012), yogurt (Park and Oh, 2005) and black raspberry juice (Kim et al., 2009) are used for raw materials in order to obtain the fermented products enhanced GABA component (Table 3). At these processes, glutamic acid contained in the natural ingredients without artificial glutamic acid (MSG) may be converted to $100 \%$ of GABA or there is a case of adding a small amount of MSG with the aim of $100 \%$ conversion of added MSG. Also, the extract of various grains such as rice bran, rice germ and mungbean were added to a certain amount of carbon source and nitrogen for the production of high concentrations of GABA (Kook et al., 2009).

\section{Fermentation conditions}

In general, the fermentation conditions for the growth of lactic acid bacteria have been equally applicable to the production of GABA. Most of lactic acid bacteria are facultative anaerobic, so additional aeration or strong agitation is not necessary. Regardless of the fermentation scale, the degree of agitation, that bacterial cells didn't subside during fermentation periods, is sufficient, and additional supply of air or oxygen is not necessary, either. The GABA is produced smoothly at a suitable temperature for the growth of strains having GABA-producing capability (Choi et al., 2006; Kook et al., 2009). However, the production of GABA is not always optimized in the fermentation condition optimized the growth of all strains. There was not difference in the production of GABA in the general $\mathrm{pH}$ range during fermentation period of lactic acid bacteria, but the productivity of GABA even fell down when the $\mathrm{pH}$ was adjusted to $\mathrm{pH} 4$ at the lag phase of cell growth. The adjustment of $\mathrm{pH}$ during fermentation period has some sort of effect on the productivity of GABA (Kang, 2002; Kim, 2009). Thus, it is reported that the adjustment of $\mathrm{pH}$ is not requested for the productivity of GABA. It is determined that the $\mathrm{pH}$ is more important in the production of GABA than other fermentation conditions because the biosynthesis mechanism of GABA is closely related to the $\mathrm{pH}$. The acidic $\mathrm{pH}$ conditions of culture broth, which is made by organic acid such as lactic acid produced during lactic acid fermentation, are necessary for GABA production by lactic acid bacteria, which convert glutamic acid into GABA. The biosynthesis mechanism of GABA is to maintain the $\mathrm{pH}$ within the cell constantly even though the environment around the cell becomes acidification, because glutamate consumes one molecule of $\mathrm{H}^{+}$by decarboxylation and raises the $\mathrm{pH}$ within the cell.

So $\mathrm{pH}$ condition of culture broth is an important factor 


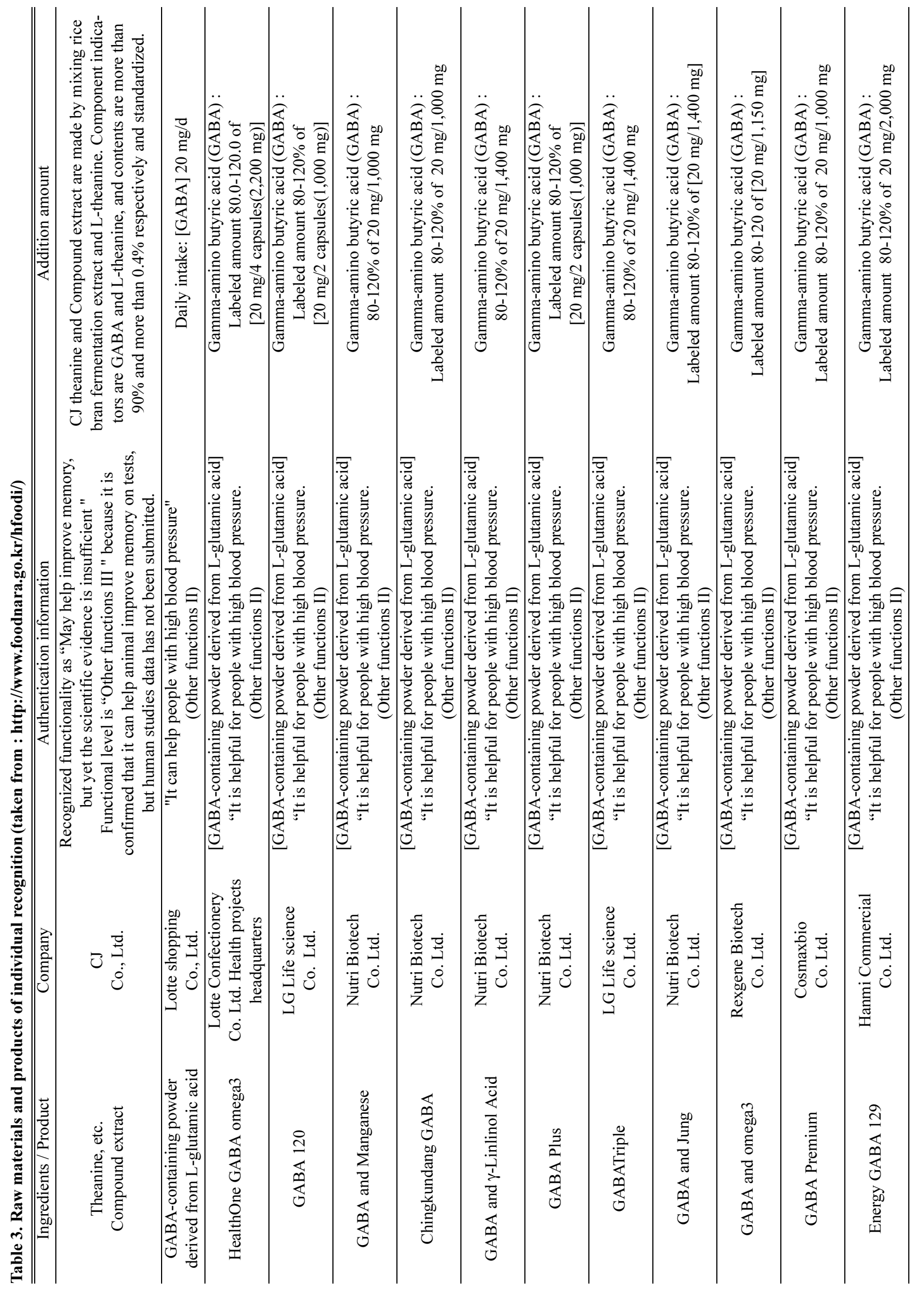


in GABA production (Fig. 3). It showed that the point of being converted to GABA of glutamic acid was from the late logarithmic growth phase when the growth of strains progressed to some extent as previously reported, and which is consistent with the report that the activity of the key enzyme, GAD for converting to GABA becomes the best in the stationary phase (Hayakawa et al., 1997). It can be seen that production of GABA is started at acidic $\mathrm{pH}$ conditions that lactic acid bacteria produce the organic acid during their growth period regardless of lactic acid bacteria strain. There is a little difference depending on the medium compositions and the wild strains, but the production of GABA is started usually from after $8 \mathrm{~h}$ and lasted up to $48 \mathrm{~h}$. It can be seen that GABA production is sustained at a low level as long as the viable cell is maintained and glutamic acid is present.

Therefore, GABA-producing strain should be fermented at the optimal temperature in order to maximize the productivity of GABA and at the non-adjusting $\mathrm{pH}$ is not required, however the $\mathrm{pH}$ environment should be acidified by the production of organic acids such as lactic acid during the culture of lactic acid bacteria. It is determined that the total activity (AU) and specific activity (AU/CFUcell) of GAD are maximized in an environment such as optimal temperature and acidic $\mathrm{pH}$ etc., additionally, the substrate, MSG, added in the culture medium, is delivered into the cells by their own antiporter system and maximize the production of GABA.

\section{GABA-producing capability}

The concentration of GABA produced by the fermenta-

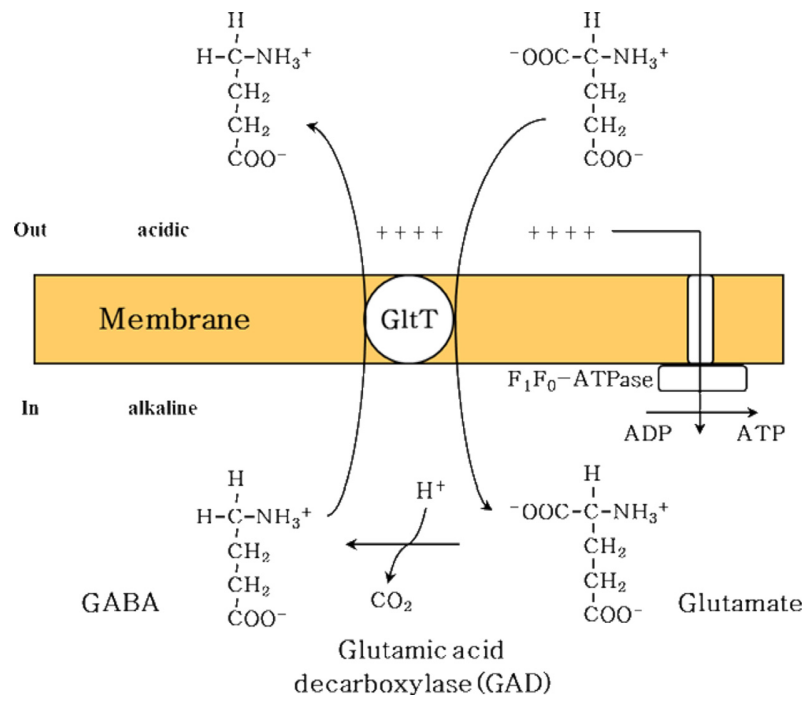

Fig. 3. Hypothetical scheme for acidic $\mathrm{pH}$ resistance mechanism and ATP production by glutamic acid decarboxylase in Lactobacillus strains (Kang, 2002). tion shows the difference depending on the basic capability of screened strains and the optimization of fermentation condition. Each strain's GABA-producing capability is how much MSG can be converted into GABA during fermentation period and the conversion rate as well as the amount of added MSG is also an important factor. Especially, in case of GABA produced for food, the merchantability is much lower by domestic emotional issues to avoid MSG when it is not converted to GABA in the fermentation broth.

Theoretical production yield of GABA can be represented by how much glutamic acid added as MSG has been converted into GABA. The molecular weight of MSG is 169 and GABA is 103.1 . When $8 \%(\mathrm{w} / \mathrm{v})$ of MSG is added per 1 liter of medium, the GABA content in the medium is $4.88 \%(\mathrm{w} / \mathrm{v})$ by calculated as $(103.1 \div 169) \times 8 \%$, if added glutamic acid is converted to $100 \%$ of GABA. In general, most of MSG distributed as a food additive on the markets is mono hydrate type and the molecular weight is 187 , so the molecular weight and the moisture content should be considered when calculating the conversion yield.

GABA-producing strain isolated from Japanese Soju produced $2 \mathrm{mM}$ level of GABA without adding glutamic acid in the early time (Yokoyama et al., 2002), according to the recent research in Korean, the fermentation broth containing over $600 \mathrm{mM}(618 \mathrm{~g} / \mathrm{L})$ of GABA could be obtained by the batch fermentation at the optimal medium added $12 \%$ of MSG (mono hydrate), at this case of fermentation, GABA production yield was $100 \%$ (Kook et al., 2010). In China, it was reported that $1,000 \mathrm{mM}$ levels of GABA has been produced by fed-batch recently (Li et al., 2010).

Accordingly, the production of GABA has been increased by screening of a new strain and optimization of fermentation conditions, and the various applications of purposes are possible.

\section{Commercialization of GABA}

Post-treatment of GABA-containing culture broth

GABA-containing culture broth is powered through the post-treatment process to make the material containing high concentrations of GABA. The post-treatment process removes water-insoluble fractions primarily, most of them were cells used in the fermentation, removed by filtration using membrane or continuous-type centrifugation. After remove the water-insoluble fractions, GABA containing broth is powdered through the spray drying add- 
ing diluting material such as maltodextrin. Generally, GABA, carbon source and nitrogen source containing in the culture broth, are very hygroscopic, so it is impossible to be powered through the spray drying if the GABA content exceeds a certain concentration. Therefore, the highest level of GABA content that are produced by spray drying is approximately $20 \%$

The crystallization process is necessary in order to increase the GABA content more than $20 \%$. In this case, it's possible to increase the GABA concentration close to $100 \%$ but there would be no benefit for the fermentation process because it costs a lot and the discrimination with chemically synthesized GABA is eliminated by removing various substances produced by lactic acid bacteria during fermentation. In addition, the marketability of GABA-containing powder increased when extracts such as rice bran, rice germ, and mung bean used as a fermentation broth (Cho et al., 2005).

Recently, various efficacies of GABA on the skin are revealed (Denda et al., 2002; Han et al., 2007) and GABA is developing as functional ingredients for the cosmetics. Using as food ingredients, GABA-containing culture broth can be used raw materials for cosmetics. However, it is necessary to remove the unique flavor of the fermentation broth and pass the decoloration in order to apply the fermentation broth to raw materials for cosmetics. The distillation method is commonly used for deodorization and the activated carbon for the decoloration mainly. In addition, preservatives that can prevent pollution and degeneration during distribution period can be added for the commercialization of liquid product.

\section{Efficacies of GABA}

The research for clinical efficacy of GABA began in earnest by identifying the effect on diseases such as insomnia, depression using defatted rice embryos enhanced the GABA content in Japan (Okada et al., 2000). After that, the various functions have shown and studies for new applications of GABA are progressing.

Utilizing the research that driving exercise-induction of rats is suppressed when added GABA to feed because of its role of inhibitory neurotransmitter, that is, weight is increased by inhibiting the movement of the unintended energy consumption, a study for utilizing the efficacy by adding GABA to feed has been conducted and it might mean the possibility of GABA as a feed additives.

Also, Bae (2008) confirmed the efficacy of GABA related to the alcohol decomposition and improvement of liver function by confirming the fact that the liver function of the mouse, which ate feed added GABA powder produced by lactic acid bacteria has improved.

This means that GABA can be used as a material with enough competitiveness in many domestic drinking populations. Also, Kim et al. (2010) conducted study on the sleep-inducing effects of GABA by obtaining the result about the significant increase of melatonin and serotonin in case of eating over a certain amount of GABA produced by lactic acid bacteria through animal test. It means that GABA can get the spotlight as the food ingredient to prevent insomnia increasing rapidly due to such a stress recently if the effectiveness is proven.

\section{Others}

"GABA" cannot be expressed in Korea yet because it is not registered in Korean Food Standards Codex and Korean Food Additives Codex. Accordingly, it is considered that GABA being distributed as a food material, is manufactured in "other food" and named "Fermented material" currently. Because the "registration" process is costly and time-consuming in Korea unlike Japan. It is because the study for GABA is continued in some small business such as ventures in most cases and the domestic market for GABA couldn't be expanded too much. Anyway, it is not possible to determine whether the registration of "GABA" was not tried by the small market or vice versa. However, several companies are try to certificate GABA as functional material utilizing a wide range of government support in recent years (Table 3 ).

A variety of physiological functions of GABA revealed so far can be both advantages and disadvantages at the same time in the commercialization of GABA, especially. Various experiments should be carried out to demonstrate the validity of function after selecting one which can highlight to consumers among the variety of physiological functions of GABA in order to certify as a functional material, all of which is difficult to have to invest a lot of money. However, it is necessary to utilize GABA which has various physiological functions. Its safety is already proved by fermented foods such as kimchi and various sauces which have been ingested traditionally. Especially, it is the material to be utilized to contribute to the national health in the domestic situation to enter the super-aging society unprecedentedly.

Also, the GABA added feed for companion livestock marketed in Japan recently and began to be supplied to the Korea through online purchase and started to apply to the factory-type livestock industry as functional ingredients.

As described above, it is known that GABA is synthe- 
sized in eukaryotes, such as plants and the degree of synthesis are affected by environmental factors. The synthesis of GABA is considered to be compete the stress that comes from environments. Therefore, it is necessary to be ingested through food or functional food for human and feed for livestock because the GABA concentration becomes lower by stress and aging.

\section{Conclusion}

We reviewed the recent trends of study related to GABA produced by fermentation in Korea. The research of utilization of GABA as a functional ingredient started in Japan and has been progressing much in China recently.

A variety of products added GABA can also be found in US as well as Japan and those are sold as the type of mixture with vitamin and healthy foods for sleep induction unlike the Orient. However, consumers in US have used synthetic GABA without any burden due to their less reluctance for synthetic products. Accordingly, a various biologically active substances produced by microorganisms are not contained and have sold in low price with the content of more than $1000 \mathrm{mg}$ for one drink. On the other hand, most of GABA products are produced by fermentation due to the reluctance on the synthetic products in Korea, China and Japan. It is considered that the continuous research for the production of GABA is needed in Korea because the GABA market is at the beginning unlike Japan. Especially, mungbean fermented broth containing GABA is exported to China as a cosmetics material, so it is expected that the GABA market in Korea will be expanded further if additional research on the skin-related efficacy of GABA is conducted.

It is determined that there are some subjects to discuss in the production of GABA by fermentation. At first, monosodium glutamate (MSG) is used as the source of glutamic acid supplied to the fermentation medium. MSG is good for the fermentation material for its solubility, reasonable price and edibility, but it has the problem that MSG may remain in culture broth if the conversion rate of MSG does not reach to $100 \%$ due to the vague reluctance on MSG surging the nation. Therefore, it is necessary to use substances other than MSG as a source of glutamic acid or find the method of adding glutamic acid in the medium after dissolving. Otherwise, the burden that should convert all of MSG during the fermentation period occurs. The second is that the sodium content of the final product increases by the residual sodium ions when MSG added during the medium is converted to the
GABA. It depends on the purpose, but the amount of sodium added to the product with GABA is small because the effective amount of GABA is also small at the level of tens to hundreds milligrams, however, the content of sodium which is one of the ingredients that should be avoided in the food as well as MSG has to be reduced. To do this, it is needed to use the method to remove the sodium ion in the culture broth after fermentation or develop a source of glutamic acid other than MSG.

It is determined that the fermentation optimization for production of GABA is not fulfilled yet despite some differences exist depend on the type of strains producing GABA. The study on the production of GABA by enzymatic conversion after separating GAD enzyme is conducted, but it can be not the fermentation product in the traditional sense. Therefore, in order to optimize the fermentation associated with the production of GABA, the $\mathrm{pH}$ adjustment at a specific time, production of high concentrations of GABA by cell recycle as well as the supply of medium and glutamic acid in the concept of continuous culture is ongoing in some sort. GABA being produced with a higher efficiency is going to be used as a material for the health of many people in aging modern times.

\section{References}

1. Abe, Y., Umemura, S., Sugimotto, K., Hirawa, N., Kato, Y., Yokoyama, T., Iwai, J., and Ishii, M. (1995) Effect of green tea rich in $\gamma$-aminobutyric acid on blood pressure on Dahl salt-sensitive rats. Am. J. Hypertens. 8, 74-79.

2. Bae, M. O. (2008) Effect of Kimchi lactic acid bacteria with high GABA producing capacity on liver function of rats administered with ethanol. Master thesis, Chonbuk National Univ., Jeonju, Korea.

3. Bae, M. O., Kim, H. J., Cha, Y. S., Lee, M. K., and Oh, S. H. (2009) Effects of Kimchi lactic acid bacteria Lactobacillus sp. OPK2-59 with high GABA producing capacity on liver function improvement. J. Korean Soc. Food Sci. Nutri. 38, 14991505.

4. Baum, G., Simcha, L. Y., Fridmann, Y., Arazi, T., Katsnelson, H., and Zik, M. (1996) Calmodulin binding to glutamate decarboxylase is required for regulation and GABA metabolism and normal development in plants. EMBO J. 15, 2988-2996.

5. Chang, J. S., Lee, B. S., and Kim, Y. G. (1992) Changes in $\gamma$ aminobutyric acid (GABA) and the main constituents by a treatment conditions and of anaerobically treated green tea leaves. Korean J. Food Sci. Technol. 24, 315-319.

6. Chen, X. X., Li, D., Lu, J. X., and Fang, F. (1997) Determination of aminobutyric acid and glutamic acid in human celebrospinal fluid by high performance liquid chromatography. Chin. J. Chromatogr. 277, 1-24. (in Chinese).

7. Cho, S. C., Kim, D. H., Park, C. S., Koh, J. H., Pyun, Y. R., and Kook, M. C. (2012) Production of GABA-rich tomato 
paste by Lactobacillus sp. fermentation. Korean J. Food Nutr. 25, 26-31.

8. Cho, S. C., Kook, M. C., and Pyun, Y. R. (2005) Development of functional ingredients enriched with GABA and evaluation of its effect. Health technology \& Infra development project. Final report. Korea.

9. Cho, Y. R., Ji, Y. C., and Hae, C. C. (2007) Producton of $\gamma$ aminobutyric acid (GABA) by Lactobacillus buchneri isolated from Kimchi and its neuroprotective effect on Neuronal cells. J. Microbio. Biotechnol. 17, 104-109.

10. Choi, S. I., Lee, J. W., Park, S. M., Lee, M. Y., Ji, G. E., Park, M. S., and Heo, T. R. (2006) Improvement of $\gamma$-aminobutyric acid (GABA) production using cell entrapment of Lactobacillus brevis GABA 057. J. Microbiol. Biotechnol. 16, 562-568.

11. Cohen, S. A. and Michaud, D. P. (1993) Synthesis of a fluorescent derivertizing reagent, 6-aminoqunonyl-N-hydroxysuccinimidyl carbonate, and its application for the analysis of hydrolysate amino acids via high performance liquid chromatography. Anal. Biochem. 211, 279-287.

12. Denda, M., Inoue, K., Inomata, S., and Denda, S. (2002) Gamma-aminobutyric acid (A) receptor agonists accelerate cutaneous barrier recovery and prevent epidermal hyperplasia induced by barrier disruption. J. Invest. Dermatol. 119, 1041-1047.

13. Fougère, F., Le Rudulier, D., and Streeter, J. G. (1991) Effect of salt stress on amino acid, organic acid, and carbohydrate composition of roots, bacteroids and cytosol of alfalfa (Medicago sativa L). Plant Physiol. 96, 1228-1236.

14. Han, D. O., Kim, H. Y., Lee, H. J., Shim, I. S., and Hahm, D. H. (2007) Wound healing activity of Gamma-aminobutyric acid (GABA) in rats. J. Microbial. Biotechnol. 17, 1661-1669.

15. Hao, R. and Schmit, J. C. (1993) Cloning of the gene for glutamate decarboxylase and its expression during condiation in Neurospora crassa. Biochem . J. 15, 887-890.

16. Hayakawa, K., Kimura, M., Kasaha, K., Matsumoto, K., Sansawa, H., and Yamori, Y. (2004) Effect of $\gamma$-aminobutyric acidenriched dairy product on the blood pressure of spontaneously hypertensive and normotensive Wista r-Kyoto rats. Br. J. Nutr. 92, 411-417.

17. Hayakawa, K., Ueno, Y., Kawamura, S., Taniguchi, R., and Oda, K. (1997) Production of $\gamma$-Aminobutyric acid by lactic acid bacteria. Seibutsu. Kogaku. 75, 239-244.

18. Higuchi, T., Hayashi, H., and Abe, K. (1997) Exchange of glutamate and $\gamma$-aminobutyrate in a Lactobacillus strain. J. Bacteriol. 179, 3362-3364.

19. Holdiness, M. R. (1983) Chromatographic analysis of glutamic acid decarboxylase in biological samples. J. Chromatogr. 277, $1-24$.

20. Ibolya, M. P. and Vasanits, A. (1999) Stability and characteristics of the $o$-phthaldialdehyde/ 3-mercaptopropionic acid and $o$-phthaldialdehyde/ $N$-acetyl- $L$-cysteine reagents and their amino acid derivatives measured by high-performance liquid chromatography. J. Chromatogr. A. 835, 73-91.

21. Jung, H. J., Lee, S. D., Cho, K. H., Park, J. C., Cho, S. B., Kim, D. U., Kim, S. U., and Kim, I. C. (2010) Feed composition with $\gamma$-aminobutyric acid and feeding method thereof. Korea Patent 10-2010-0096806.

22. Kang, M. S. (2002) A study on ã-amino butyric acid production by Lactobacillus sakei B2-16. Master thesis, Yonsei Univ.,
Seoul, Korea.

23. Kim, D. S. (2009) Study on the fermentation in lactic acid bacteria for the production of $\gamma$-aminobutyric acid. Master thesis, Hannam Univ., Daejeon, Korea.

24. Kim, G. S. (2010) Swine feed additive using natural medicinal herbs and a preparation method thereof. Korea Patent 100962235.

25. Kim, J. Y., Lee, M. Y., Ji, G. E., Lee, Y. S., and Hwang, K. T. (2009) Production of ã-aminobutyric acid in black raspberry juice during fermentation by Lactobacillus brevis GABA100. Int. J. Food Microbiol. 130, 12-16.

26. Kim, S. S., Oh, S. H., Jeong, M. H., Cho, S. C., Kook, M. C., Lee, S. H., Pyun, Y. R., and Lee, H. Y. (2010) Sleep-inductive effect of GABA on the fermentation of mono sodium glutamate (MSG). Korean J. Food Sci. Technol. 42,142-146.

27. Kim, T. J., Sung, C. H., Kim, Y. J., Jung, B., M., Kim, E. R., Choi, W. S., Jung, H. K., Chun, H. N., Kim, W. J., and Yoo, S. H. (2007) Effect of a soaking-fermentation-drying process on the isoflavone and $\gamma$-aminobutyric acid contents of soybean. Food Sci. Biotechnol. 16, 83-89.

28. Komatsuzaki, N., Shima, J., Kawamoto, S., Momose, H., and Timura, T. (2005) Production of $\gamma$-aminobutyric acid (GABA) by Lactobacillus paracasei isolated from traditional fermented foods. Food Microbiol. 22, 497-504.

29. Kono, I. and Himeno, K. (2000) Changes in $\gamma$-aminobutyric acid content during beni-koji making. Biosci. Biotechnol. Biochem. 64, 617-619.

30. Kook, M. C., Cho, S. C., Cheigh, C. I., Park, H., Kim, S. S., Jeong, M. H., Pyun, Y. R., and Lee, H. Y. (2009) Study on $\gamma$ aminobutyric acid (GABA) production by Lactobacillus sakei B2-16. Food Eng. Pro. 20, 183-189.

31. Kook, M. C., Seo, M. J., Cheigh, C. I., Pyun, Y. R., Cho, S. C., and Park, H. (2010) Enhanced production of $\gamma$-aminobutyric acid using rice bran extracts by Lactobacillus sakei B216. J. Microbiol. Biotchnol. 20, 763-766.

32. Korea Rural Economic Institute (KREI), Agricultural and stockbreading products statistics. Available from: http://www.krei. re.kr/kor/stastistics/stastistics_main.php. Korean Food Standards Codex. (2011) 104-105.

33. Lee, J. D. (2009) Method for farming poultry using environment-friendly poultry feed, capable of improving immunity without antibiotics. Korea Patent 10-0923771.

34. Lee, J. H., Kwon, S. M., Seo, S. H., Park, Y. S., Kim, Y. B., Kim, S. K., and Paik, H. D. (2008) Screening of a natural feed additive having anti-viral activity against influenza A/H5N1. Korean J. Food Sci. Technol. 28, 512-516.

35. Leventhal, A. G., Wang, Y. C., Pu, M. L., Zhou, Y. F., and Ma, Y. (2003) GABA and its agonists improved visual cortical function in senescent monkeys. Science 300, 812-815.

36. Li, H., Qiu, T., Huang, G., and Cao, Y. (2010) Production of gamma-aminobutyric acid by Lactobacillus brevis NCL912 using fed-batch fermentation. Microb. Cell Fact. 9, 85-91.

37. Lim, D. H., Park, J. K., Kim, H. S., Ki, G. S., Lee, H. J., Kwon, E. G., Kim, C. H., and Kim, S. B. (2011) Effect of feeding nattokinase as natural feed additives on milk production and blood metabolites in lactating dairy cows. Korean $J$. Org. Agri. 19, 553-563.

38. Magoto, B., Shinobu, S., and Mikio, D. (2004) Method of fat- 
tening poultry. PCT/JP2002/02163, Korea Patent 10-20047008015

39. Masuda, K., Guo, X., Uryu, N., Hagiwara, T., and Watabe, S. (2008) Isolation of marine yeasts collected from the pacific ocean showing a high production of $\gamma$-aminobutyric acid. Biosci. Biotechnol. Biochem. 72, 3265-3272.

40. Ministry for Food, Agriculture, Forestry and Fisheries. Announcement No. 2010-3, Bounds and criteria of Harmful feed.

41. Miwako, K., Miyuki, S., Akira, Y., and Koji, Y. (1999) Accumulation of GABA in brown rice by high pressure treatment. J. Jpn. Soc. Food Sci. Technol. 46, 329-333.

42. Moon, H. G. (1998) Metabolic and Physiological changes under Immunologic stress in animals- A mini review. RDA. $J$. Livestock Sci. 40, 72-80.

43. Mountfort, D. O. and Pybus, V. (1992) Regulatory influence on the production of gamma-aminobutyric acid by a marine pseudomonad. Appl. Environ. Microbiol. 58, 237-242.

44. Nakamura, T., Matsubaysahi, T., Kamachi, K., Hasegawa, T., Ando, Y., and Omori, M. (2000) $\gamma$-aminobutyric acid (GABA)rich chlorella depresses the elevation of blood pressure in spontaneously hypertensive rats (SHR). J. Agr. Chem. Soc. Jpn. 74, 907-909.

45. Nomura, M., Kimoto, H., Someya, Y., Furugawa, S., and Suzuki, I. (1998) Production of $\gamma$-aminobutyric acid by cheese starter during cheese ripening. J. Dairy Sci. 81, 1486-1491.

46. Oh, N. R. (2006) Physiological characteristics of Lactobacillus cripatus RMK 567 isolated from milk and optimization of GABA producing condition. Master thesis, Sungkyunkwan Univ., Suwon, Korea.

47. Oh, S. H. and Oh, C. H. (2003) Brown rice extracts with enhanced levels of GABA stimulate immune cells. Food Sci. Biotechnol. 12, 248-252.

48. Okada, T., Sugishita, T., Murakami, T., Murai, H., Saikusa, T., Horino T., Onoda, A., Kajimoto, O., Takahashi, R., and Takahashi, T. (2000) Effect of defatted rice germ enriched with GABA for sleeplessness, depression, autonomic disorder by oral administration. J. Jpn. Soc. Food Sci. Technol. 47, 596-603.

49. Park, J. S., Nam, S. J., Choi, W. K., Pyun, Y. R., Cho, S. C., Kook, M. C., Lee, C. W., and Jung, S. Y. (2005) Lactic acid bacteria culture of mung bean and the preparation method of the same, and the cosmetic composition comprising the same. Korea Patent 10-2005-0061136.

50. Park, K. B. and Oh, S. H. (2005) Production and characterization of GABA rice yogurt. Food Sci. Biotechnol. 14, 518-522.

51. Park, K. B. and Oh, S. H. (2006) Isolation and characterization of Lactobacillus buchneri strains with high $\gamma$-aminobutyric acid producing capacity from naturally aged cheese. Food Sci. Biotechnol. 15, 86-90.

52. Park, K. B. and Oh, S. H. (2007) Production of yogurt with enhanced level of gamma-aminobutyric acid and valuable nutrients using lactic acid bacteria and germinated soybean extract. Bioresource Technol. 98, 1675-1679.

53. Rhodes, D., Handa, S., and Bressan, R. A. (1986) Metabolic changes associated with adaptation of plant cells to water stress. Plant Physiol. 82, 890-903.
54. Saikusa, T., Horino, T., and Moki, Y. (1994) Accumulation of $\gamma$-aminobutyric acid (GABA) in the germ during water soaking. Biosci. Biotechnol. Biochem. 58, 2291-2292.

55. Sawai, Y., Yamaguchi, Y., Miyama, D., and Yoshitomi, H. (2001) Cycling treatment of anaerobic and aerobic incubation increase the content of $\gamma$-aminobutyric acid in tea shoots. Amino Acids 20, 331-334.

56. Seok, J. H., Park, K. B., Kim, Y. H., Bae, M. O., Lee, M., K., and Oh, S. H. (2008) Production and characterization of kimchi with enhanced levels of $\gamma$-aminobutyric acid. Food Sci. Biotechnol. 17, 940-946.

57. Sethi, M. L. (1993) Enzyme inhibition X: colorimetric method for determining gabase activity and its comparison with a spectrophotometric method. J. Pharm. Biomed. Anal. 11, 613-617.

58. Shelp, B. J., Bown, A. W., and McLean, M. D. (1999) Metabolism and functions of gamma-aminobutyric acid. Trends Plant Sci. 4, 446-452.

59. Shin, J. W., Kim, D. G., Lee, Y. W., Lee, H. S., Shin, K. S., Choi, C. S., and Kwon, K. S. (2007) Isolation and characterization of Lactobacillus brevis AML15 producing $\gamma$-aminobutyric acid. J. Life Sci. 17, 970-975.

60. Song, Y. H., Lee, Y. J., and Yang, W. S. (1998) Stress and welfare of animal. Gangwon Univ. Animal Resource Research 12, 125-135.

61. Tcherkas, Y. V., Kartsova, L. A., and Krasnova, I. N. (2001) Analysis of amino acids in human serum by isocratic reversed phase high-performance liquid chromatography with electrochemical detection. J. Chromatogr. A. 913, 303-308.

62. The Agriculture, Fisheries \& Livestock's News. Available from: http://www.aflnews.co.kr/aflnews/index.asp. Accessed Jan. 17, 2011.

63. Tsuji, K., Ichikawa, T., Tanabe, N., Abe, S., Tarui, S., and Nakagawa, Y. (1992) Antihypertensive activity of beni-koji extracts and $\gamma$-aminobutyric acid in spontaneously hypertensive rats. Jpn. J. Nutr. 50, 285-291.

64. Tsushida, T. and Murai, T. (1987) Conversion of glutamic acid to $\gamma$-aminobutyric acid in tea reaves under anaerobic conditions. Agric. Biol. Chem. 51, 2856-2871.

65. Ueno, H. (2000) Enzymatic and structural aspects on glutamate decarboxylase. J. Mol. Catal. B Enzym. 10, 67-69.

66. Ueno, Y., Hayakawa, K., Takahashi, S., and Oda, K. (1997) Purification and characterization of glutamate decarboxylase from Lactobacillus brevis IFO 12005. Biosci. Biotechnol. Biochem. 61, 1168-1171.

67. Yang, S. Y., Lü, F. X., Lu, Z. X., Bie, X. M., Jiao, Y., Sun, L. J., and Yu, B. (2008) Producton of $\gamma$-aminobutyric acid by Streptococcus salivarius subsp. thermophilus Y2 under submerged fermentation. Amino Acids 34, 473-478.

68. Yokoyama, S., Hiramatsu, J., and Hayakawa, K. (2002) Production of $\gamma$-amminobutyric acid from alcohol distillery lees by Lactobacillus brevis IFO 12005. J. Biosci. Bioeng. 93, 95-97.

69. Wang, H. F., Tsai, Y. S., Lin M. L., and Ou, A. S. (2006) Comparison of bioactive components in GABA tea and green tea produced in Taiwan. Food Chem. 96 , 648-653.

$\overline{\text { (Received 2013.2.19/Revised 2013.6.19/Accepted 2013.6.19) }}$ 